\title{
Disruptive Effect of Midazolam on Fear Memory Reconsolidation: Decisive Influence of Reactivation Time Span and Memory Age
}

\author{
Silvia G Bustos', Héctor Maldonado² and Víctor A Molina*,1 \\ 'Departamento de Farmacología, Facultad de Ciencias Químicas, Universidad Nacional de Córdoba, Haya de la Torre y Medina Allende, \\ Córdoba, Argentina; 'Laboratorio de Neurobiología de la Memoria, Departamento de Fisiología y Biología Molecular, IFIBYNE-CONICET, \\ Pabellón II, Facultad de Ciencias Exactas y Naturales (CI 428EHA), Universidad de Buenos Aires, Buenos Aires, Argentina
}

Benzodiazepine (BDZ) administered shortly after retrieval disrupts the reconsolidation of fear memory. In this research, we explored the way in which different factors that limit the emergence of such process may affect BDZ's disruptive effect on fear memory reconsolidation. Animals were conditioned in a contextual fear paradigm; the consolidated memory was reactivated by exposure to the associated context for different periods of time that were followed by midazolam (MDZ) administration. We also studied MDZ amnesic effect after reactivating fear memories of several ages. We finally analyzed the effectiveness of different MDZ doses in preventing the reconsolidation of different age fear memories. The memory trace was disrupted following MDZ when the reactivation session lasted 3-5 min but it was not after a briefer I-min reactivation period. Over a 10-min reactivation session, all animals gradually reduced their fear response, which indicates the emergence of the extinction process. When tested, MDZ rats exhibited a robust fear, suggesting that MDZ impaired the consolidation of extinction. In a 3-min reactivation session, MDZ $(1-1.5 \mathrm{mg} / \mathrm{kg})$ prevented the reconsolidation of recently acquired memories. A 21 -day-old fear memory was only vulnerable to MDZ at a $1.5 \mathrm{mg} / \mathrm{kg}$ dose with a reactivation session of 5 and not $3 \mathrm{~min}$, whereas a 36-day-old memory was only disrupted with a higher MDZ dose $(3 \mathrm{mg} / \mathrm{kg})$ regardless of the reactivation trial's duration. This study demonstrated MDZ's interference on fear-memory reconsolidation within a relatively short reactivation period in recently acquired memories. Over longer reexposure, MDZ disrupts the consolidation of extinction. A longer duration of the reexposure session, as well as higher MDZ doses, is required to prevent the reconsolidation process of remote fear memories. Neuropsychopharmacology (2009) 34, 446-457; doi:I0. I038/npp.2008.75; published online 28 May 2008

Keywords: contextual fear memory; reconsolidation; midazolam; memory age; reactivation

\section{INTRODUCTION}

Accumulated experimental data support the argument that after retrieval, consolidated memory may become temporarily vulnerable to disruption for a limited period of time (Przybyslawski and Sara, 1997; Przybyslawski et al, 1999; Nader, 2003; Debiec and Ledoux, 2004; Duvarci and Nader, 2004). Such vulnerability is followed by a stabilization process - usually referred to as reconsolidation - that requires de novo protein synthesis. Memory reconsolidation has been demonstrated across a variety of species (Anokhin et al, 2002; Suzuki et al, 2004; Sangha et al, 2003; Pedreira

*Correspondence: Dr VA Molina, Departamento de Farmacología, Facultad de Ciencias Químicas, Universidad Nacional de Córdoba, Haya de la Torre y Medina Allende, Ciudad Universitaria, 5000 Córdoba, Argentina, Tel: + 540351 4334437, Fax: + 540351 4334420, E-mail: vmolina@fcq.unc.edu.ar

Received 4 January 2008; revised 26 March 2008; accepted 21 April 2008 and Maldonado, 2003), including humans (Walker et al, 2003; Forcato et al, 2007), and under different learning and memory paradigms motivated by either aversive or rewarding stimuli (Dudai and Eisenberg, 2004; Lee et al, 2005). All this evidence strongly supports the notion that reconsolidation represents an evolutionarily conserved mnemonic process and accounts for the universality of this phenomenon. According to the reconsolidation hypothesis, the reactivation of a previously consolidated memory trace may be achieved by an appropriate reminder cue of the original association. This procedure can render this susceptible-to-disruption trace by selective pharmacological interventions including benzodiazepine (BDZ) administration, when administered shortly after reactivation (Bustos et al, 2006).

It is well known that GABAergic neurotransmission influences the emergence of memory processes (Izquierdo and Medina, 1991; McGaugh, 2000). Previous findings showed that allosteric modulators of $\gamma$-amino butyric acid-A (GABA-A) receptors such as $\mathrm{BDZ}$ agents (positive 
modulators) or inverse agonist (negative modulators) of $\mathrm{BDZ}$ sites are effective in affecting these processes. BDZ compounds induce anxiolysis, sedation, and muscle relaxation (Thiebot, 1985; Venault et al, 1986; McNamara and Skelton, 1991; McNamara et al, 1993) and, under certain conditions, produce amnesia. Data derived from humans (Beracochea, 2006) and from laboratory animals have all shown that BDZ agents can impair memory. Moreover, prior administration of an antagonist of BDZ sites reversed BDZ-induced amnesia (Savic et al, 2005) whereas the administration of the inverse agonist resulted in a promnesic effect, indicating that BDZ sites are implicated in the formation of memory. BDZ's disruptive effect has been observed following administration either pre- or posttraining in diverse learning and memory paradigms (Gafford et al, 2005). Such an effect was also reported after both BDZ intraamygdala (Dickinson-Anson and McGaugh, 1993) and BDZ intradorsal hippocampus (Gafford et al, 2005) infusions. Consistent with such findings, Bustos et al (2006) have recently demonstrated that midazolam (MDZ), a short-acting BDZ, affects fear memory reconsolidation.

Although there is consensus regarding the emergence of reconsolidation, the reactivation-induced memory lability associated with the reminder depends on a number of parameters. Both knowledge and identification of the latter are indispensable requirements for an understanding of this memory phase. The present paper was conducted to examine two parametrical conditions of the reconsolidation process and their interplay in determining the degree of the reactivation-induced lability after the reminder's presentation. The parameters under study were memory age and the reactivation duration (presentation of the conditioned stimulus, CS, without the unconditioned stimulus, US). The former critically influences the labile phase after reactivation. What is more, older memories are less susceptible to interference than newer or recently acquired ones (Milekic and Alberini, 2002; Suzuki et al, 2004; Frankland et al, 2006). The latter, the duration of the reactivation session, is another crucial factor in the reconsolidation process as reactivation of a consolidated memory for a short time span is likely to result in reconsolidation. Besides, longer duration can lead to extinction, whereas, an even shorter reactivation time can result in an incomplete reconsolidation (Tronson and Taylor, 2007). Consequently, the resulting behavior of the subsequent CS presentation (test) is critically influenced by the duration of the reactivation session (Eisenberg et al, 2003; Pedreira and Maldonado, 2003; Suzuki et al, 2004).

Therefore, in the present study, animals were trained in a conditioned contextual fear paradigm. Consolidated memory was reactivated for different periods of time by presenting the CS (context cue) without the US (foot shock) followed by immediate MDZ administration. Freezing was scored 1 day later, during the first test, and 10 days later, during the second test. In addition, MDZ efficiency as an interfering agent after reactivating fear memories of several ages was also studied. Animals were trained and reexposed to the context at different times after training. Immediately after reexposure, rats were administered with $\mathrm{MDZ}$ and tested 1 and 10 days later. Finally, we compared the efficacy of different MDZ doses in interfering fear memory reconsolidation among fear memories of different ages.
To address this question, animals were trained and reactivated after different periods of time and administered with diverse doses of $\mathrm{MDZ}$ following reactivation at each age. All animals were tested for their fear in response to the associated context both 1 and 10 days later.

\section{MATERIALS AND METHODS}

\section{Animals}

Adult male Wistar rats (60-day old, weighing between 280 and $320 \mathrm{~g}$ ) from our colony of the Department of Pharmacology of the Facultad de Ciencias Químicas, Universidad Nacional de Córdoba were used. All animals were housed in standards laboratory Plexiglas cages in groups of three per cage. Food and water were available ad libitum. Animals were maintained on a 12-h light/dark cycle (lights on at 0700-1900 hours) and at a room temperature of $21-23^{\circ} \mathrm{C}$. The protocols used were approved by the Animal Care Committee of the Facultad de Ciencias Químicas, Universidad Nacional de Córdoba and are consistent with the standards outlined in the NIH Guide for the Care and Use of Laboratory Animals. The number of animals used, as well as their suffering, was kept to the minimum possible needed to accomplish the goals of this study.

\section{Drugs}

Midazolam (Gobbi Novag SA, Buenos Aires, Argentina) was diluted in sterile isotonic saline $(\mathrm{SAL}, 0.9 \% \mathrm{w} / \mathrm{v})$ to a concentration of $1,1.5$, and $3 \mathrm{mg} / \mathrm{ml}, \mathrm{MDZ}$ was administered intraperitoneally (i.p.). The total volume of drug or an equivalent amount of SAL was $1.0 \mathrm{ml} / \mathrm{kg}$ in all cases.

\section{Apparatus}

The conditioning environment was designated as context A (A). This environment was made of gray plastic $(20 \times 23 \times 20 \mathrm{~cm})$ with clear lid and the floor consisted of 10 parallel stainless steel grid bars, each measuring $4 \mathrm{~mm}$ in diameter and spaced $1.5 \mathrm{~cm}$ apart (center to center), enclosed within a sound-attenuating chamber. The grid floor was attached to a scrambled shocker (Ugo Basile Biological Research Apparatus, Italy) to provide foot shock. Background noise was supplied by ventilation fans and shock scramblers. The illumination was provided by a $2.5 \mathrm{~W}$ white light bulb.

A second distinctive environment designated as context B (B) was made as different as possible from the context used for training, and was located in a different room. The novel context was made of wood and had a transparent plastic lid, black walls, and black rubber floor, dimensions being $33 \times 25 \times 33 \mathrm{~cm}$. The chamber was brightly illuminated by three lights.

Both environments (A and B) were cleaned with water before and after utilization. Experiments were always performed between 1100 and 1400 hours with the experimenters unaware of the treatment condition.

\section{Behavioral Procedure}

Each experiment consisted of three phases: conditioning, reexposure (reactivation session), and testing sessions. An 
acoustically isolated room was used to run the training and the other phases (reexposure and tests) of the experiment.

Contextual fear conditioning. The conditioning procedure used was similar to the one previously described (Isoardi et al, 2004; Bustos et al, 2006). Rats were habituated to handling and injected with SAL for at least 2 days prior to the start of each experiment. At the beginning of each experimental day, animals were transported from the colony room to the experimental room, where they remained in their cages. During conditioning, reexposure (reactivation session), and testing sessions, a different acoustically isolated room was used. Training consisted in placing each rat in the chamber (A) and allowing a 3 min acclimation period (pre-shock period). After this period, rats received three foot shocks $(0.25 \mathrm{~mA}, 3 \mathrm{~s}$ duration at inter-shock interval $30 \mathrm{~s}$; unconditioned stimuli). Animals remained in the chamber for an additional $2 \mathrm{~min}$ period (post-shock period) and were subsequently placed in their home cages and returned to the colony room.

Reexposure session (reactivation). After training, subjects were reexposed to the training context $(A)$ without shocks for different periods of time $(1,3,5,7$, or $10 \mathrm{~min})$ depending on the experiment performed.

Test sessions. Test 1 was always assessed $24 \mathrm{~h}$ after the reexposure to $\mathrm{A}$ by re-placing the rats in the training environment for $5 \mathrm{~min}$. Test 2 was conducted 10 days after test 1 . The behavior of each rat was continuously videotaped to score freezing during the 3 min pre-shock period, during the 2 min post-shock period, during the reexposure period, and during testing. Freezing behavior was scored at the end of the experiment by a person who was blind with regard to the experimental condition of each animal. The total time spent freezing in each period was quantified (in seconds) using a stopwatch and expressed as the percentage of total time. Freezing, a commonly used index of fear in rats (Blanchard and Blanchard, 1969), was defined as a total absence of body and head movement except that associated with breathing.

The first series of experiments were designed to evaluate the effect of MDZ administration on the reconsolidation of a contextual fear memory after different periods of reexposure to the training context (A). The experiment was performed in three consecutive daily phases (day 1, training; day 2, reexposure; and day 3, test 1) and a final test (test 2) on day 13. Animals were randomly assigned to two experimental groups (SAL or MDZ) for each reexposure time. Rats were trained as previously described and reexposed to A 1 day later either for $1,3,5$, or $10 \mathrm{~min}$ (reactivation procedure). Immediately after reactivation, animals were administered either $\mathrm{MDZ}(1.5 \mathrm{mg} / \mathrm{kg}$, i.p.) or SAL. After 1 day, rats were relocated in A and their freezing scored for a 5-min period (test 1). Rats were then returned to their home cages without any further manipulation. In addition, to analyze whether the effect of MDZ was transient or persistent, freezing was subsequently tested (test 2) for $5 \mathrm{~min}$ in A 10 days after test 1 . The data obtained were statistically analyzed by separate one-way ANOVA with repeated measures comparing drug treatment (SAL vs
MDZ) across trials (reexposure, test 1, and test 2) at each time of reexposure $(1,3,5$, or $10 \mathrm{~min})$. This analysis was repeated for each time of reexposure $(1,3,5$, or $10 \mathrm{~min})$.

The second series of experiments were designed to evaluate the influence of memory age on MDZ's effect on the reconsolidation of a contextual fear memory. Animals were randomly assigned to two experimental groups (SAL or MDZ) and trained as previously described. Memory was reactivated either $1,7,21$, or 36 days later and rats were administered either MDZ (1.5 mg/kg, i.p.) or SAL immediately after reactivation. After 1 day, rats were relocated in the training environment and their freezing video-recorded for a 5-min period (test 1). Rats were then returned to their home cages without any further manipulation. In addition, freezing from all animals was subsequently scored (test 2) for $5 \mathrm{~min}$ in A 10 days after test 1. The data obtained were statistically analyzed by separate one-way ANOVA with repeated measures comparing drug treatment (SAL vs MDZ) across trials (reexposure, test 1 and test 2). This analysis was repeated for each memory age $(1,7,21$, or 36 days).

The third series of experiments were designed to evaluate the interaction between memory age and the different doses of MDZ used on the reconsolidation of fear contextual memory. To investigate a potential difference in the sensitivity of MDZ to disrupt reconsolidation of different age memories, animals were trained as previously described and randomly assigned to three groups. One group of rats was reexposed to A 7 days after training and injected with $\mathrm{SAL}$ or $\mathrm{MDZ} 1$ or $1.5 \mathrm{mg} / \mathrm{kg}$, i.p. immediately after reexposure. Another group was reexposed to A 21 days after conditioning and injected with SAL or MDZ 1 or $1.5 \mathrm{mg} / \mathrm{kg}$ i.p. after reactivation. At 36 days after conditioning, the last group of rats was reexposed to $\mathrm{A}$ and subsequently injected with SAL or MDZ 1.5 or $3 \mathrm{mg} / \mathrm{kg}$, i.p. At $24 \mathrm{~h}$ after the reexposure session, all rats were reexposed to $\mathrm{A}$ and their freezing scores recorded (test 1). The data obtained were statistically evaluated by separated one-way ANOVA comparing SAL with different doses of MDZ at each memory age $(7,21$, or 36 days).

To test whether the potential impairment induced by $\mathrm{MDZ}$ is context specific, an additional group of animals was trained. After 7, 21, or 36 days, rats were placed in a novel context ( $B$, no-reactivation procedure) for different periods of time ( 3 or $5 \mathrm{~min}$ ). After B exposure, animals were injected with SAL or MDZ (1.5 or $3 \mathrm{mg} / \mathrm{kg}$ ). The test was conducted $24 \mathrm{~h}$ after the no-reactivation session by re-placing the rats in $\mathrm{A}$ for $5 \mathrm{~min}$. Fear memory was evaluated as previously described.

The data obtained from SAL- and MDZ-treated rats (no-reactivation (B) and test) were statistically analyzed by separate one-way ANOVA with repeated measures at each memory age $(7,21$, or 36 days).

\section{Statistical Analysis}

Results were expressed as mean \pm SEM. Significant ANOVAs were followed by post hoc Newman-Keuls analysis to enable specific group comparison $(p<0.05$ was regarded as significant). 


\section{RESULTS}

MDZ Disrupts Contextual Fear Memory

Reconsolidation when Administered within 3-5 min of A Reexposure (Reactivation Session) but it is Ineffective after a 1-min Reexposure

Midazolam $(1.5 \mathrm{mg} / \mathrm{kg})$ administered immediately after reexposure to $\mathrm{A}$ for $1 \mathrm{~min}$ had no effect on memory retention at test 1 (Figure $1 \mathrm{~b}$ ). Rats treated with SAL or MDZ displayed similar levels of freezing at both tests (tests 1 and 2) thus revealing that reconsolidation is not affected by MDZ under this condition. An ANOVA showed no interaction between drug treatment and trials tests $(\mathrm{F}(2,24)=0.69, p=0.51)$. Reconsolidation after longer reexposure periods ( 3 or $5 \mathrm{~min}$ ) is disrupted by $\mathrm{MDZ}$ administration (Figure $1 \mathrm{c}$ and $\mathrm{d}$ ). In the 3-min exposure group, an ANOVA showed a significant effect of drug treatment $(\mathrm{F}(1,12)=15.98, p<0.01)$, a significant effect of trials tests $(\mathrm{F}(2,24)=74.08, p<0.01)$, and a significant drug treatment $\times$ trials tests interaction $(\mathrm{F}(2,24)=25.53$, $p<0.01)$. The post hoc analysis revealed that MDZadministered rats exhibited significantly less freezing than SAL-administered rats during both test $1(p<0.01)$ and test $2(p=0.04)$.
Moreover, SAL- and MDZ-treated rats exhibited significantly less freezing on test 2 than on test 1 , indicating a progressive diminution of conditioned freezing, which in turn may suggest extinction learning $(p<0.01, p=0.04$, respectively).

In the 5-min reexposure groups, an ANOVA revealed the effect of drug treatment $(\mathrm{F}(1,18)=38.43, p<0.01)$, a significant effect of trials tests $(\mathrm{F}(2,36)=35.67, p<0.01)$, and a significant drug treatment $\times$ trials tests interaction $(\mathrm{F}(2,36)=10.07, p<0.01)$. The post hoc analysis revealed that MDZ-treated rats showed significantly less freezing than SAL-treated animals during both test $1(p<0.01)$ and test $2(p<0.01)$. In addition, SAL-treated rats displayed significantly less freezing on test 2 than on test 1 , probably indicating the emergence of extinction $(p<0.01)$.

\section{MDZ Administered after a Prolonged (10 min) Reactivation Session Impaired the Consolidation of Extinction of Fear Memory}

The effect of MDZ administration after a prolonged reactivation session on subsequent fear memory is shown in Figures $2 b$ and $c$. As expected, no difference was found between SAL and MDZ groups in their freezing response
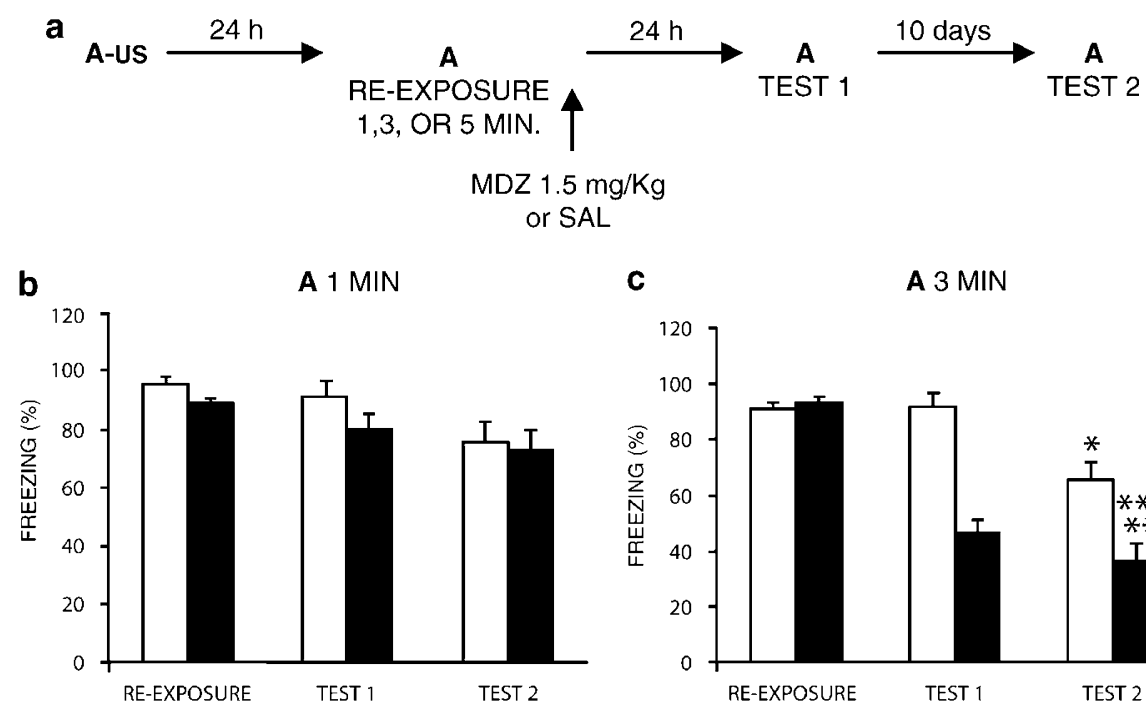

C

A 3 MIN
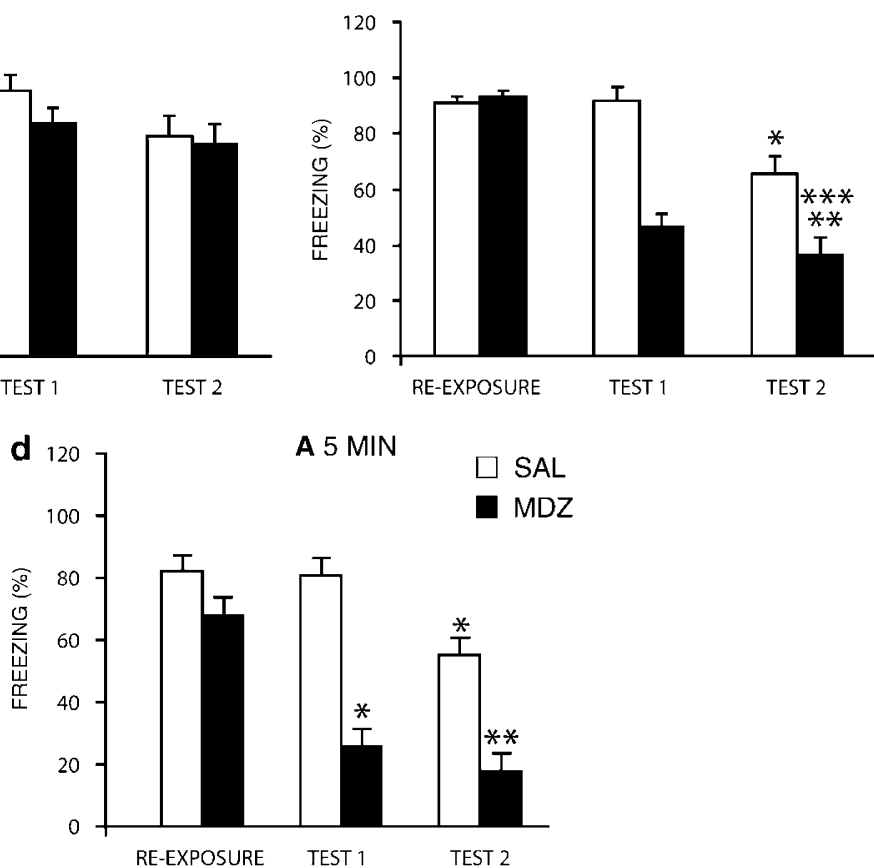

Figure I Effect of midazolam (MDZ) $1.5 \mathrm{mg} / \mathrm{kg}$ administration after reexposure to A for different periods of time. (a) Experimental design used with data presented below. (b) MDZ $1.5 \mathrm{mg} / \mathrm{kg}$ administration after a brief reexposure (I min) has no effect on the reconsolidation process. (c) MDZ I.5 mg/kg injected after $3 \mathrm{~min}$ or (d) after a 5 min reexposure produced a significant reduction of freezing behavior on tests I and 2 . Data are the mean \pm SEM percentage of time spent freezing during reexposure to $A(I, 3$, or $5 \mathrm{~min}$ ), and during tests $I$ and 2 ( $n=7 / / 0$ per group). *Significantly different than saline (SAL) group during test I $(p<0.01)$; **significantly different than SAL group during test $2(p<0.04)$; and *** significantly different than MDZ group during test I $(p=0.04)$. 


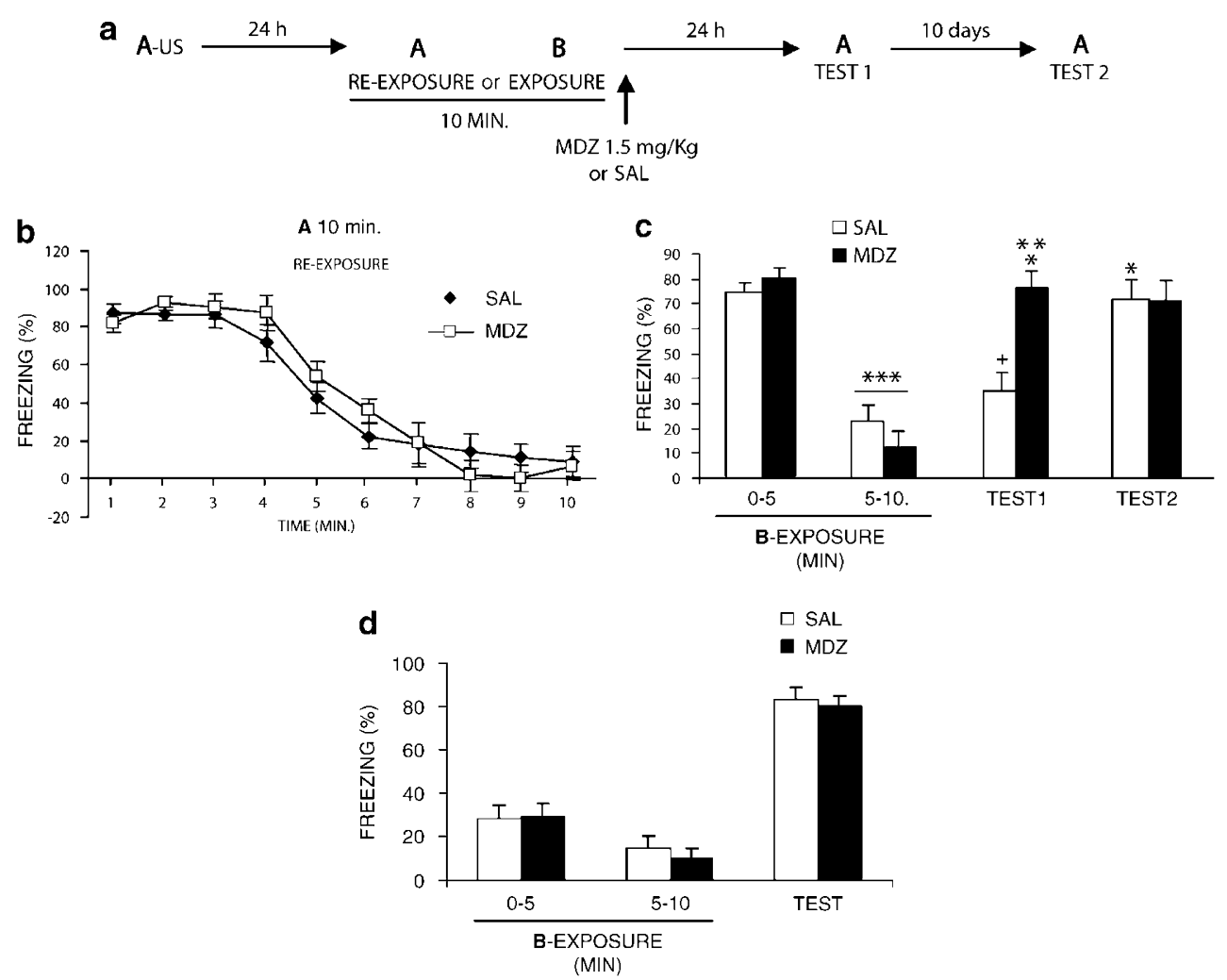

Figure 2 Effect of midazolam (MDZ) $1.5 \mathrm{mg} / \mathrm{kg}$ administration after a $10 \mathrm{~min}$ reexposure session to $\mathrm{A}$ or after a 10 min exposure to B. (a) Experimental design used with data presented below. (b) Freezing behavior displayed by both groups during each minute along the 10 min reexposure session. (c) MDZ $1.5 \mathrm{mg} / \mathrm{kg}$ administration after the $10 \mathrm{~min}$ reexposure to A preserved freezing evaluated on test I, indicating that MDZ impaired the consolidation of fear extinction. (d) Similar levels of freezing between saline (SAL)- and MDZ-treated rats $(1.5 \mathrm{mg} / \mathrm{kg})$ after the 10 min exposure to B were observed during the test. Data are the mean \pm SEM percentage of time spent freezing during the reexposure session $(I 0$ min), during exposure to $B$, during tests $\mid$ and 2 ( $n=7 / 8$ per group). *Significantly different than SAL group during test I $(p<0.0 \mathrm{I})$; **ignificantly different than MDZ group during reexposure $5-10$ min $(p<0.0 \mathrm{I})$; ***** significantly different than SAL and MDZ group during reexposure $0-5 \mathrm{~min}(p<0.0 \mathrm{I}) .{ }^{+}$Significantly different than SAL group during reexposure $0-5$ min $(p<0.0 \mathrm{I})$.

during reexposure. Interestingly, over the course of the 10 min reexposure session both groups (SAL and MDZ) showed a gradual reduction in their freezing levels, with virtually no freezing at the end of the reexposure session (Figure 2b). What is more, there was significantly less freezing on the last $5 \mathrm{~min}$ than on the first $5 \mathrm{~min}$ during reexposure (Figure 2c) thus suggesting that the longer reexposure may result in the acquisition of extinction. Moreover, when memory was assessed 1 day later, SALtreated animals froze significantly less than MDZ-treated rats (Figure 2c, test 1). An ANOVA showed a significant effect of trials tests $(F(3,39)=34.89, p<0.01)$ and a significant drug treatment $\times$ trials tests interaction $(\mathrm{F}(3,39)=8.09, p<0.01)$. A post hoc analysis revealed that both groups (SAL and MDZ) performed significantly less freezing on the last $5 \mathrm{~min}$ of reexposure than on the first $5 \mathrm{~min}(p<0.01$; Figure 2c). In addition, MDZ-treated animals performed significantly more freezing than SALtreated ones during test 1 ( $p<0.01$; Figure $2 c)$. MDZ-treated rats showed higher fear levels in test 1 than the one exhibited during the last $5 \mathrm{~min}$ of reexposure $(5-10 \mathrm{~min}$; $p<0.01)$. In addition, MDZ-treated animals exhibited relatively high levels of freezing during test 1 , behavior comparable to the freezing displayed during the initial 5 min reexposure session. In contrast, during test $1, \mathrm{SAL}$ animals froze significantly less than during the first $5 \mathrm{~min}$ of reexposure $(p<0.01)$ thus supporting the view that prolonged reexposure leads to the formation of an extinction memory; whereas MDZ interfered with the retention of extinction. The post hoc analysis also revealed that the extinguished fear response in SAL-treated rats returned in a subsequent reexposure. In fact, these animals exhibited significantly more freezing on test 2 than on test 1 suggesting the occurrence of spontaneous recovery $(p<0.01)$. In summary, all these findings suggest that a prolonged reexposure to the associated context results in the formation of an extinction memory in control rats; whereas MDZ blocks the retention of fear extinction when administered after prolonged reexposure to the conditioning context.

To evaluate whether the impairment induced by MDZ on the consolidation of fear extinction is context specific, an additional group of animals was trained and placed in a novel context for a period of $10 \mathrm{~min}$ (B, no-extinction training procedure) the following day. At the end of exposure, animals were subdivided into two groups, and injected with SAL or MDZ $1.5 \mathrm{mg} / \mathrm{kg}$. The following day, the test was conducted by re-placing the rats in A for $5 \mathrm{~min}$ and evaluating their fear memory. Similar levels of freezing were observed between SAL- and MDZ-treated rats during the 
first $5 \mathrm{~min}$ of exposure to $\mathrm{B}$, on the last $5 \mathrm{~min}$ of exposure, and during the test (Figure 2d). An ANOVA showed no drug treatment $\times$ trial tests interaction $(\mathrm{F}(2,26)=0.24, p=0.79)$. Therefore, the effect of MDZ on the retention of extinction depends on the prolonged reexposure to the associated context and cannot be attributed to nonspecific effects of MDZ on the behavior exhibited during the test.

\section{MDZ Blocks the Reconsolidation of Recent}

(1 and 7 Days) but not Remote (21 and 36 Days)

Contextual Fear Memories when Administered

After a 3-min Reactivation Period

Animals were trained for fear conditioning as previously described. After 1, 7, 21, or 36 days, they were placed back into the training context for $3 \mathrm{~min}$ (A reexposure). Immediately after reexposure, rats were administered with SAL or MDZ $1.5 \mathrm{mg} / \mathrm{kg}$. Memory was assessed twice: 1 day after reexposure (test 1 ) and 10 days after test 1 (test 2). MDZ treatment disrupted the reconsolidation of recent ( 1 and 7 days; Figures $3 \mathrm{~b}$ and c) but not of remote memories ( 21 and 36 days; Figures $3 \mathrm{~d}$ and e). An ANOVA showed a significant drug treatment $\times$ trials tests interaction on $1-(\mathrm{F}(2,24)=25.53, p<0.01)$ and 7-day memory $(\mathrm{F}(2,34)=15.24, p<0.01)$. The post hoc analysis revealed that rats injected with MDZ showed significantly less freezing than SAL-treated ones during test 1 ( 1 day $p<0.01 ; 7$ days $p<0.01)$ and test $2(1$ day $p=0.04 ; 7$ days $p<0.01)$. In addition, SAL- and MDZ-treated animals displayed significantly less freezing on test 2 than on test 1
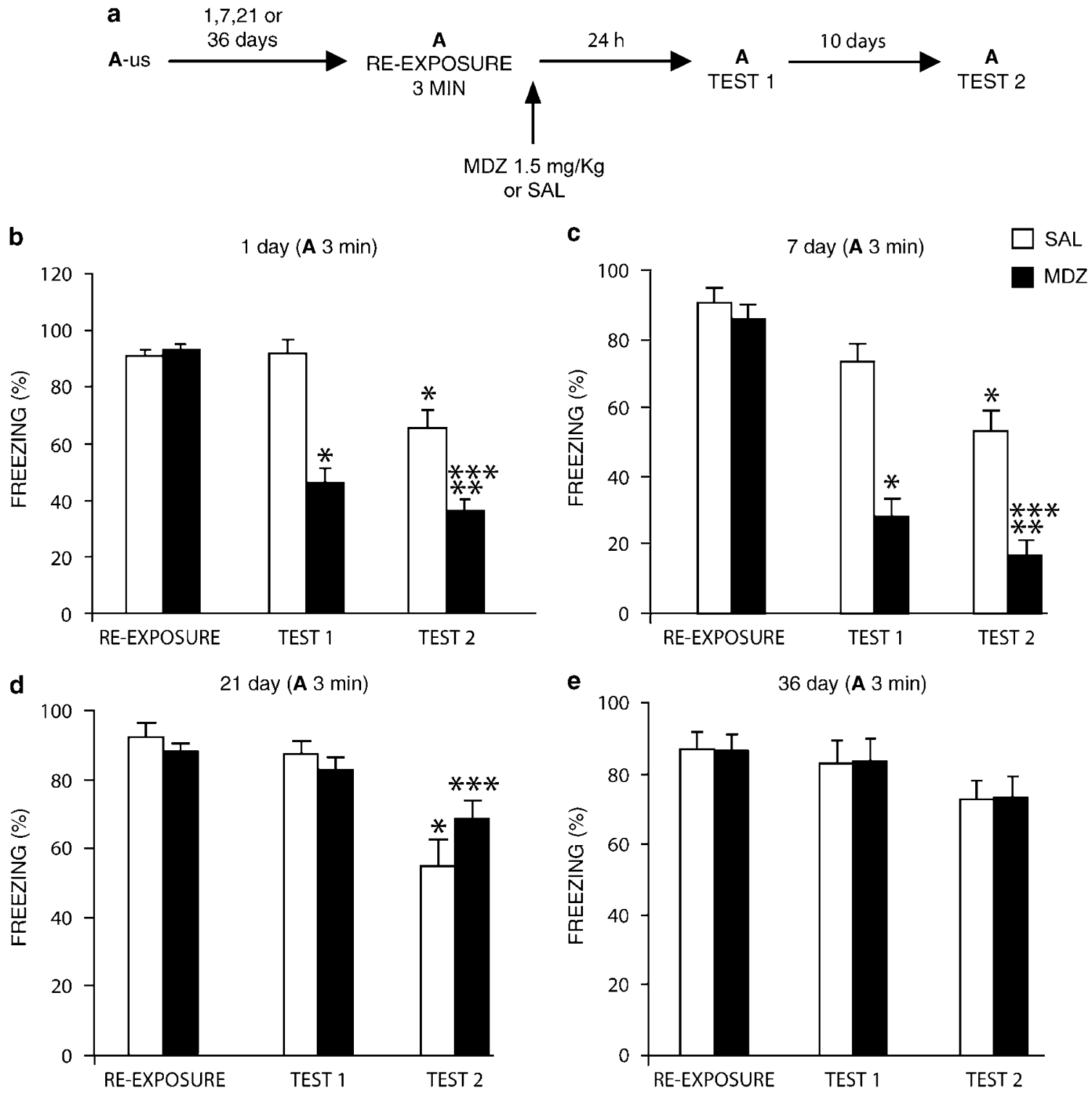

Figure 3 Effect of midazolam (MDZ) $1.5 \mathrm{mg} / \mathrm{kg}$ administration at different time intervals between training and reexposure session to A. (a) Experimental design used with data presented below. MDZ $1.5 \mathrm{mg} / \mathrm{kg}$ administration immediately after a 3 min reexposure session disrupted fear memory reconsolidation of a (b) I or (c) 7-day memory. Administration of MDZ I.5 mg/kg following a 3 min reexposure did not disrupt reconsolidation of fear memory in 21 -day (d) or in 36-day memories (e). Data are the mean \pm SEM percentage of time rats spent freezing during reexposure to $A(3 \mathrm{~min})$ and during tests $I$ and 2 $(n=7 /$ I I per group). *Significantly different than saline $(S A L)$ group during test I $(p<0.01)$; ***ignificantly different than SAL group during test 2 ( $p \leqslant 0.04)$; *****ignificantly different than MDZ group during test I $(p \leqslant 0.04)$. 
probably reflecting extinction memory after repeated drugfree reexposure to the associated context ( 1 day, $p<0.05 ; 7$ days, $p<0.05)$. In contrast, an ANOVA on the 21-day memory revealed a significant effect of trials tests $(\mathrm{F}(2,32)=29.02, p<0.01)$ and no interaction between treatment $\times$ trials tests $(F(2,34)=3.26, p=0.05)$. These findings show absence of effect of MDZ $1.5 \mathrm{mg} / \mathrm{kg}$ on the memory reconsolidation under this condition. As it can be seen in Figure 3d (21-day memory), SAL- and MDZ-treated animals displayed significantly less freezing on test 2 than on test 1 , which indicates the emergence of fear-memory extinction $(p \leqslant 0.02)$. On a 36 -day memory (Figure $3 e$ ), an ANOVA revealed no interaction between treatment $\times$ trials tests $(\mathrm{F}(2,28)=7.73, p<0.01)$ thus further indicating the absence of the MDZ $1.5 \mathrm{mg} / \mathrm{kg}$ effect on the reconsolidation process. In summary, these findings show that MDZ $1.5 \mathrm{mg} / \mathrm{kg}$ administered after a 3 min reactivation period affects fear memory reconsolidation in recently acquired memories but not in remote ones.

MDZ Interferes with the Reconsolidation of a 21-Day Fear Memory in 5-min Reexposure Sessions but not with this Process in a 36-Day Memory

The duration of the reactivation session is an important variable in reconsolidation experiments. Animals were trained as previously described and reexposed to the conditioning context for $5 \mathrm{~min} 21$ or 36 days later. Immediately after reexposure, rats were injected either SAL or MDZ $1.5 \mathrm{mg} / \mathrm{kg}$ and subsequently tested in the associated context (tests 1 and 2). As depicted in Figures $4 \mathrm{~b}-\mathrm{d}$, al groups showed similar levels of freezing during the reexposure session. Fear memory was only disrupted by MDZ in the 21-day memory group (Figure $4 \mathrm{~b}$ ). An ANOVA showed a significant treatment effect $(\mathrm{F}(1,14)=13.72$, $p<0.01)$, trials tests effect $(\mathrm{F}(2,28)=25.51, p<0.01)$, and drug treatment $\times$ trials tests interaction $(\mathrm{F}(2,28)=8.76$, $p<0.01$ ). A post hoc analysis revealed that rats injected with MDZ showed significantly less freezing than SAL-injected ones during both test $1(p<0.01)$ and test $2(p=0.04)$. Moreover, SAL-treated rats exhibited significantly less freezing on test 2 than on test 1 suggesting the emergence of extinction $(p=0.02)$. In contrast, MDZ $1.5 \mathrm{mg} / \mathrm{kg}$ did not affect reconsolidation of a 36-day memory under a 5-min reexposure period (Figure $4 \mathrm{c}$ ). An ANOVA revealed no effect of trials tests $(\mathrm{F}(2,32)=2.09, p=0.14)$. Moreover, no drug treatment $\times$ trials tests interaction was found $(\mathrm{F}(2,32)=1.81$, $p=0.18$ ). Furthermore, MDZ did not affect the reconsolidation of a 36-day memory even after a longer reexposure period $(7 \mathrm{~min})$. In fact, SAL- and MDZ-treated animals exhibited similar levels of freezing at both test 1 and test 2 (Figure 4d). An ANOVA showed a significant effect of trials

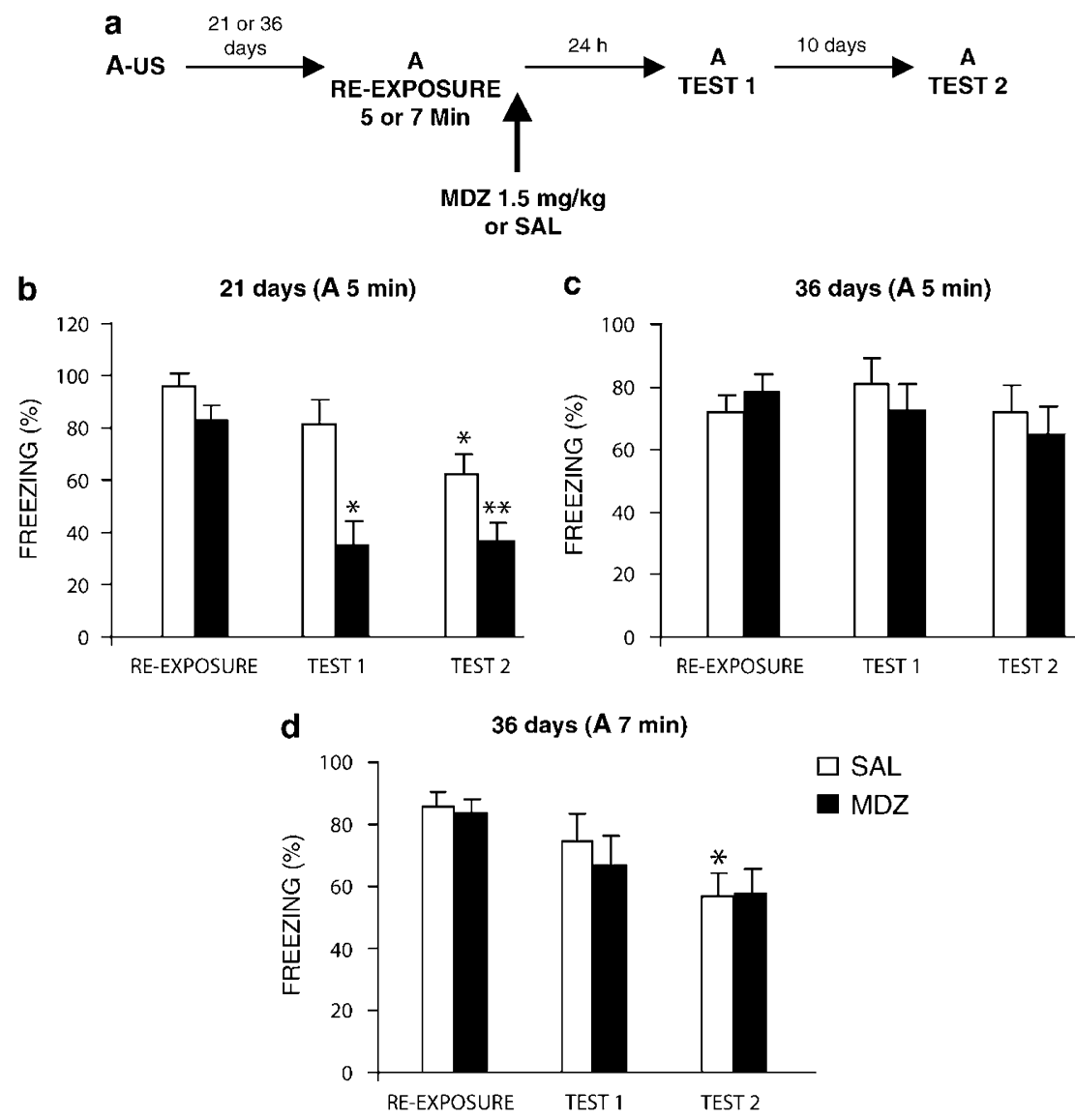

Figure 4 Effect of midazolam (MDZ) $1.5 \mathrm{mg} / \mathrm{kg}$ administration after retrieval of a 21 - (5 min reexposure) or 36 -day fear memories (5 or 7 min reexposure). (a) The behavioral procedure used in this experiment. (b) MDZ $1.5 \mathrm{mg} / \mathrm{kg}$ disrupted the reconsolidation process when administered after a $5 \mathrm{~min}$ reexposure period in a 21 -day-old memory. MDZ $1.5 \mathrm{mg} / \mathrm{kg}$ does affect reconsolidation of a 36-day-old memory neither after $5 \mathrm{~min}$ (c) nor after 7-min reexposure (d). Data are the mean \pm SEM percentage of time spent freezing during reexposure to $A(5$ or 7 min), and during tests I and 2 . ( $n=8 / 9$ per group). *Significantly different than saline (SAL) group during test I $(p<0.01)$; **significantly different than SAL group during test 2 ( $p=0.04)$. 
tests $(\mathrm{F}(2,32)=16.85, p<0.01)$ and no interaction between treatment $\times$ trails tests $(\mathrm{F}(2,32)=0.39, p=0.68)$. A post hoc analysis revealed that rats injected with SAL showed significantly less freezing on test 2 than on test 1 suggesting the emergence of extinction $(p<0.01)$. Therefore at the dose used in the current experiment, MDZ does not affect reconsolidation of a 36-day fear memory regardless of the duration of the reexposure period.

\section{Effect of MDZ on Reconsolidation of a Fear Contextual Memory Depends on Memory Age and MDZ Dose Interaction}

In this experiment, we examined the effect of different doses of $\operatorname{MDZ}(1,1.5$, and $3 \mathrm{mg} / \mathrm{kg})$ on the reconsolidation process of different age memories (7,21, and 36 days). The first group of rats was trained as usual and 7 days later their memory was reactivated ( 3 min reexposure). Next, animals were injected with either SAL or MDZ 1.0 or $1.5 \mathrm{mg} / \mathrm{kg}$ and 1 day later, they were tested as usual. As expected, a significant reduction of freezing was found in MDZ-treated rats at both doses, supporting the view that $\mathrm{MDZ}$ prevents the reconsolidation of a 7-day fear memory (Figure 5b). An ANOVA showed a significant treatment effect $(\mathrm{F}(2,28)=$ $10.54, p<0.01)$. A post hoc analysis revealed that rats injected with MDZ at either dose exhibited significantly less freezing than SAL-treated ones during the test (MDZ: $1 \mathrm{mg} / \mathrm{kg}$, $p=0.01$; MDZ: $1.5 \mathrm{mg} / \mathrm{kg}, p<0.01$ ). A second group of rats was trained as above and reexposed to the associated context 21 days after conditioning. Immediately after a 5min reexposure, animals were administered with either SAL or MDZ 1.0 or $1.5 \mathrm{mg} / \mathrm{kg}$. Reconsolidation of fear memory was only disrupted in animals administered with the higher dose of $\operatorname{MDZ}(\mathrm{F}(2,22)=18.88, p<0.01$; Figure $5 \mathrm{c})$. A post hoc analysis revealed that only animals injected with MDZ $1.5 \mathrm{mg} / \mathrm{kg}$ showed significantly less freezing than SALtreated ones during the test $(p<0.01)$. When memory was reactivated ( 5 min reexposure), 36 days after fear conditioning, MDZ had an amnesic effect at the only dose of $3 \mathrm{mg} / \mathrm{kg}$. $(\mathrm{F}(2,22)=10.52, p<0.01)$. A post hoc analysis revealed that only the MDZ-injected ( $3 \mathrm{mg} / \mathrm{kg})$ group showed significantly less freezing than SAL-treated animals during the test $(p<0.01$; Figure $5 \mathrm{~d})$. Altogether, these findings demonstrate that the passage of time between conditioning and reexposure determines the effectiveness of the MDZ disruptive effect on fear memory reconsolidation.

An additional experiment was performed to discard the possibility that the greater resistant to reconsolidation blockade observed in older memories was due to the age of the animals (96 days) at the moment of the reactivation session (36 days after conditioning). A group of 96-day-old rats were trained as previously described and reexposed to A 1 day later for $3 \mathrm{~min}$. Immediately after reactivation, animals were injected with either SAL or MDZ $1.5 \mathrm{mg} / \mathrm{kg}$. The following day, the test was conducted as usual by re-placing the rats in the training environment (A) for $5 \mathrm{~min}$ and evaluating their fear memory. Freezing was subsequently tested 10 days after test 1 . Similar levels of freezing were observed between SAL- and MDZ-treated rats during the reactivation session (SAL 79 $\pm 9.12 \%$; $\mathrm{MDZ}$ $72.18 \pm 9.12 \%$ ) and a significant reduction of freezing was found in MDZ-treated rats during test 1 and test 2 a
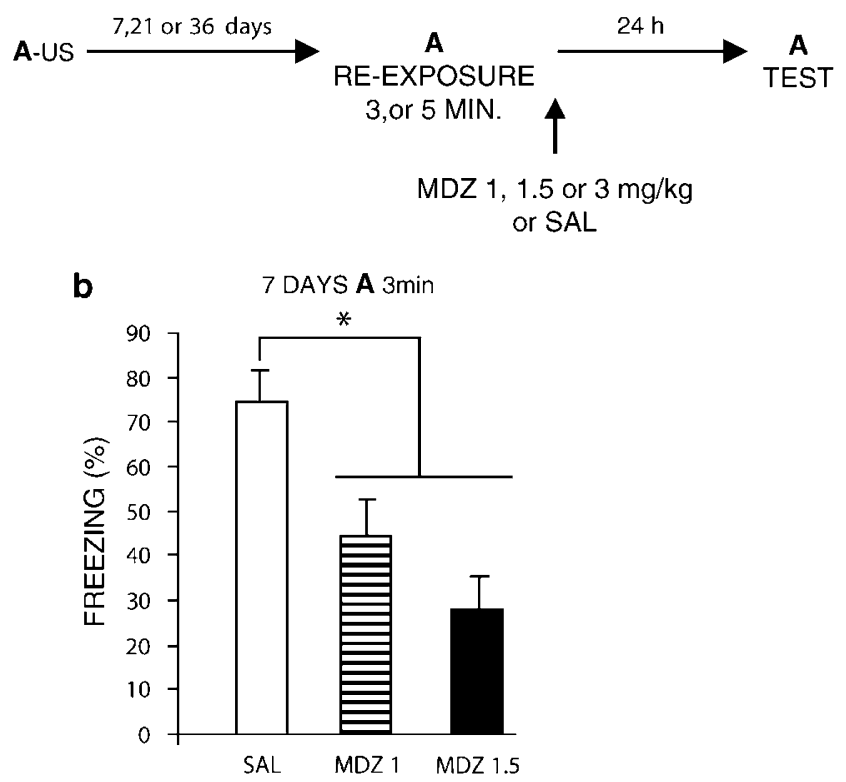

C 21 DAYS A 3 min
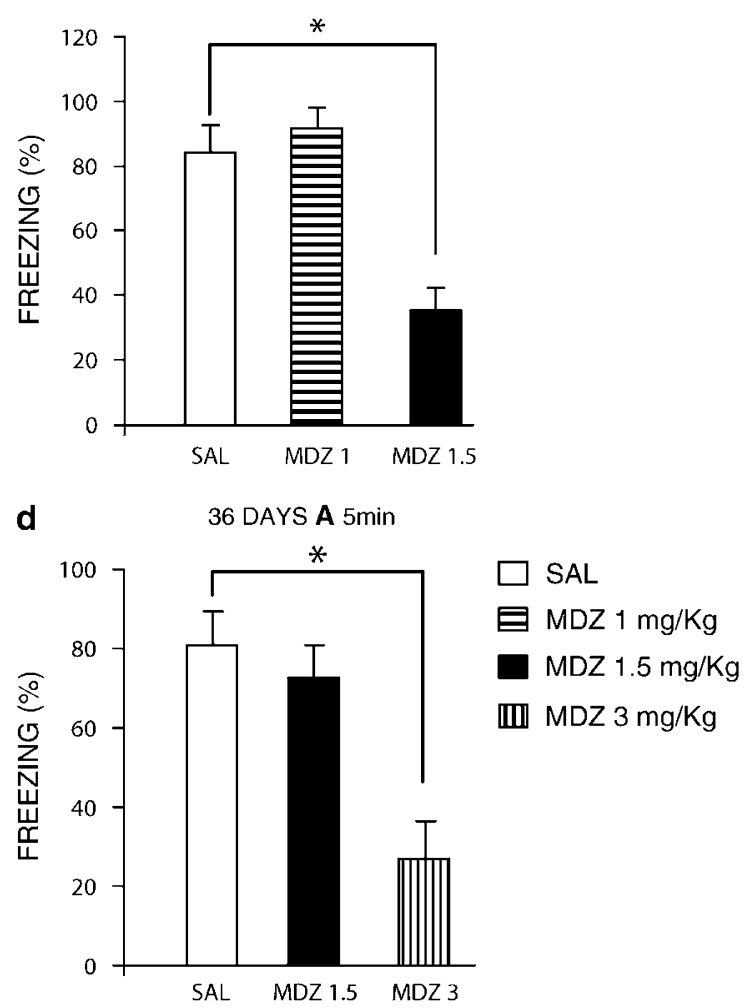

Figure 5 Effect of different doses of midazolam (MDZ) administration after the reactivation of different age memories. (a) The behavioral procedures used in the experiment. (b) MDZ I and $1.5 \mathrm{mg} / \mathrm{kg}$ disrupted the reconsolidation of a 7-day fear memory after a $3 \mathrm{~min}$ reexposure, (c) MDZ I.5 but not I mg/kg disrupted the reconsolidation of a 21 -day fear memory after a $5 \mathrm{~min}$ reexposure. (d) MDZ 3 but not $1.5 \mathrm{mg} / \mathrm{kg}$ disrupted fear memory reconsolidation after a $5 \mathrm{~min}$ reexposure in a 36-day memory. Data are the mean \pm SEM percentage of time spent freezing during the test, reexposure to $A$ ( 3 or 5 min; $n=8 / 1$ I per group). *Significantly different than saline $(\mathrm{SAL})$ group $(p<0.0 \mathrm{I})$. 
(test 1, SAL $90.71 \pm 8 \%$; MDZ $29.83 \pm 8 \%$; test 2 , SAL $77.54 \pm 8 \%$; MDZ $21 \pm 8 \%$ ), supporting the view that MDZ prevents the reconsolidation of a recent contextual fear memory despite the age of the animal. An ANOVA showed a significant effect of drug treatment $(\mathrm{F}(1,14)=16.71$, $p=0.01)$, a significant effect of trial tests $(\mathrm{F}(2,28)=$ 11.562, $p<0.01)$, and a significant drug treatment $\times$ trial tests interaction $(\mathrm{F}(2,28)=14.855, p<0.01)$. The post hoc analysis revealed that $\mathrm{MDZ}$-administered rats exhibited significantly less freezing than SAL-administered rats during both test $1(p=0.03)$ and test $2(p=0.03)$.

\section{MDZ's Disruptive Effect on Reconsolidation of a Fear Contextual Memory is Contingent on Memory Reactivation}

To determine whether the disruption on memory reconsolidation caused by MDZ was dependent on memory reactivation, distinct groups of rats were trained as usual (in A). Next, groups were exposed to a novel context (B) for different periods of time $(3$ or $5 \mathrm{~min}$ ) and at different intervals between conditioning and B exposure $(7,21$, or 36 days). Immediately after $B$ exposure, animals were injected with either SAL or MDZ at different doses depending on memory age. The following day, all animals were tested in A. MDZ $1.5 \mathrm{mg} / \mathrm{kg}$ was administered immediately after exposure to $\mathrm{B}$ for 3 min 7 days after the training. As it can be seen in Figure 6b, the drug had no effect on memory retention at the test. An ANOVA showed no effect of drug treatment $(\mathrm{F}(1,14)=0.44, p=0.52)$, a significant effect of trials tests $(F(1,14)=64.51, p<0.01)$, and no interaction between drug treatment $\times$ trials tests $(F(1,14)=0.63$, $p=0.44)$. The post hoc analysis revealed that SAL- and MDZ-treated rats exposed to B displayed significantly lower levels of freezing when compared to SAL- and MDZ-treated rats during the test $(p<0.01)$. MDZ $1.5 \mathrm{mg} / \mathrm{kg}$ had no effect on memory when rats were subjected to a 5 min exposure to B, 21 days after the training (Figure 6c). An ANOVA showed no effect of drug treatment $(\mathrm{F}(1,17)=0.26, p=0.62)$, a significant effect of trials tests $(\mathrm{F}(1,17)=19.56, p<0.01)$, and no interaction between drug treatment $\times$ trials tests $(\mathrm{F}(1,17)=0.13, p=0.73)$. The post hoc analysis revealed that nonreactivated animals injected with either SAL or MDZ displayed significantly less levels of freezing during $B$ exposure than those exhibited by SAL- or MDZ-treated rats during the test $(p<0.03)$.

Finally Figure $6 \mathrm{~d}$ shows that MDZ $3 \mathrm{mg} / \mathrm{kg}$ administered immediately after a $5 \mathrm{~min}$ exposure to the novel environment (no reactivation) 36 days after conditioning had no effect on fear memory at the test. An ANOVA showed no effect of drug treatment $(\mathrm{F}(1,16)=3.67, p=0.08)$, trials tests $(\mathrm{F}(1,16)=1.28, p=0.28)$, and no interaction between drug treatment $\times$ trials tests $(\mathrm{F}(1,16)=0.08, p=0.78)$. Similar levels of freezing during the exposure to the novel context (no reactivation) and during the test were observed between SAL- and MDZ-injected animals. These findings indicate that reexposure to the associated environment (reactivation session) is required for the disruptive effect of $\mathrm{MDZ}$ on memory reconsolidation regardless of memory age.

\section{DISCUSSION}

The present findings demonstrate that MDZ administered after reactivation interferes fear memory reconsolidation, an effect that is critically dependent on the duration of the reactivation trial. When MDZ was administered after a very brief period of reactivation (1 min), SAL- and MDZ-treated animals exhibited similar levels of freezing, indicating that the memory trace remained immune to the disruptive effect of the BDZ compound. The significant fear observed during reexposure is a sign of reactivation of the learned association between the context and the aversive stimulus. Therefore, recall per se does not induce vulnerability to interference when memory is reactivated for a very brief period of time. Similarly, Suzuki et al (2004) and Lee et al (2008) show that anisomycin administration following
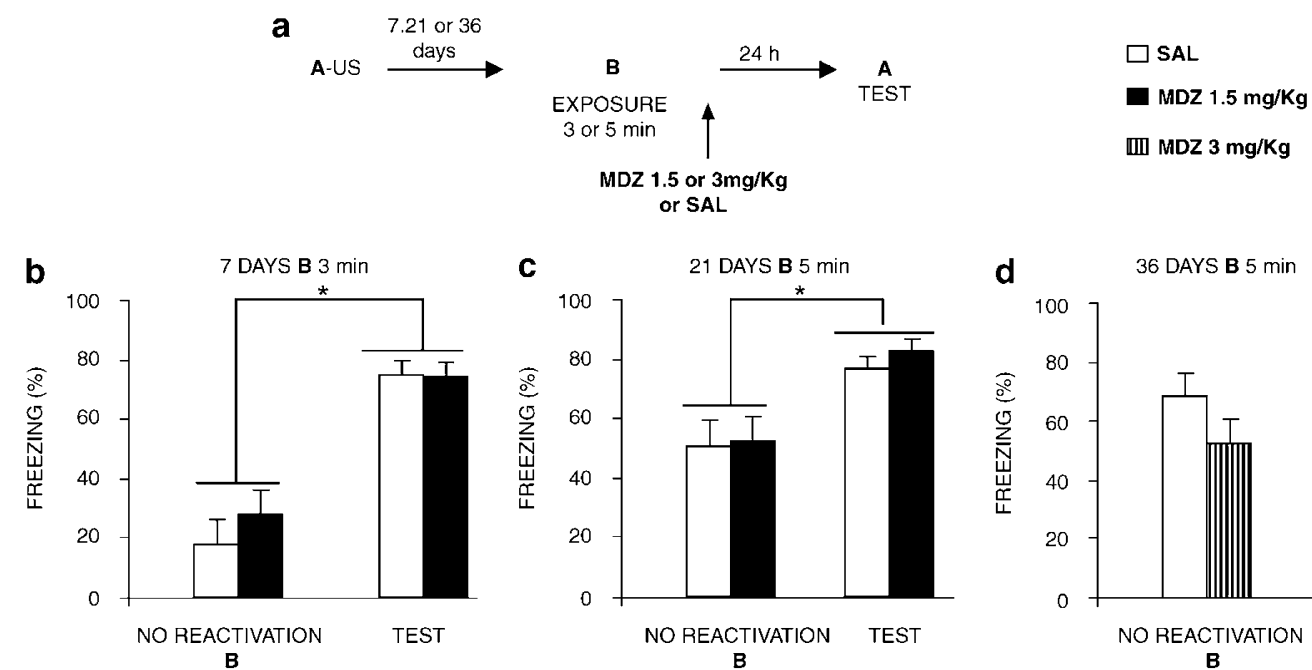

IIII MDZ $3 \mathrm{mg} / \mathrm{Kg}$ or SAL
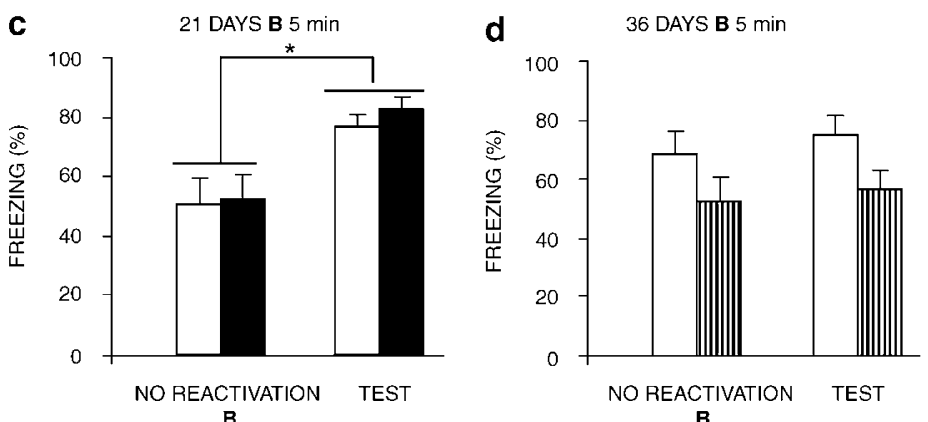

Figure 6 Midazolam (MDZ) administration after exposure to a novel environment ( $B$, no-reactivation session) did not affect memory when tested in the associated context (A). (a) Experimental design used with data presented below. Effect of MDZ I.5 mg/kg after: (b) a 3- or (c) 5-min exposure to the novel context. (d) Effect of MDZ $3 \mathrm{mg} / \mathrm{kg} /$ i.p. following 5-min exposure to the novel context. Data are the mean \pm SEM percentage of time spent freezing during exposure to B ( 3 or $5 \mathrm{~min}$ ) and during the test ( $n=8 / 10$ per group). *Significantly different than saline (SAL) and MDZ B (no-reactivation) groups ( $p \leqslant 0.03$ ). 
1 min retrieval session did not affect subsequent freezing. Furthermore, Lee et al (2008) report the inability of brief reexposure to induce the protein degradation necessary to destabilize the preexisting fear memory. Finally, the absence of MDZ vulnerability after 1 min context exposure confirms that interference after memory reactivation requires the fulfillment of several conditions rather than the single memory retrieval (Pedreira et al, 2004; Forcato et al, 2007). When the reactivation was prolonged up to $3-5 \mathrm{~min}$, the memory trace became gradually vulnerable to disruption as MDZ-treated rats showed less fear than controls. Interestingly and in accordance with prior findings (Bustos et al, 2006), the lack of fear exhibited during test 2 reflects a persistent amnesia. Both control and MDZ groups displayed a gradual reduction of their freezing along the reactivation session when the reexposure to the CS was prolonged for $10 \mathrm{~min}$. In fact, the level of fear during the last minutes of reactivation was significantly lower than that exhibited during the initial minutes, presumably indicating that rats began to extinguish the fear response. The low level of fear exhibited during test 1 by control animals previously reexposed to the $\mathrm{CS}$ for $10 \mathrm{~min}$ further confirmed this presumption. What is more, during test 2, the extinguished fear returned suggesting the emergence of spontaneous recovery. Thus, a single but prolonged reexposure to the context without reinforcement in our experimental paradigm resulted in extinction. Consistent with previous findings (Tronson and Taylor, 2007), the current results show that brief reexposure leads to reconsolidation whereas a prolonged reactivation session induces extinction and confirm the view that the duration of the reactivation session is a crucial variable that determines subsequent memory (Debiec et al, 2002; Suzuki et al, 2004; Pedreira and Maldonado, 2003). In contrast, MDZ rats exhibited a robust fear during both the first and the second tests after a 10-min reactivation session. This suggests that $\mathrm{MDZ}$ impaired the consolidation of extinction. In fact, MDZ-treated animals exhibited a stronger memory for the original learning than control rats, that is, the opposite result to the expected one of blocking reconsolidation. Our findings further confirm that the reduction produced by $\mathrm{MDZ}$ administration on fear memory is not due to the facilitation of the extinction process but to the MDZ interference on reconsolidation (Bustos et al, 2006). Extinction is a new active learning process during which the organism learns that the CS no longer predicts the occurrence of the US (Bouton, 2004; Bouton et al, 2006). This acquisition results in a memory that competes with and temporarily suppresses the memory formed during the original association (Myers and Davis, 2002). On the basis of present findings, it is evident that MDZ interferes with both the processes, reconsolidation and consolidation of extinction. Consequently, if reconsolidation is the dominant process (brief reexposure to the $\mathrm{CS}$ ), $\mathrm{MDZ}$ blocks the original memory and no signs of fear memory are observable. In contrast, if extinction is induced and becomes the dominant process (long reexposure to the $\mathrm{CS}$ ), MDZ interferes with the consolidation of extinction and freezing emerges as the main behavioral expression during a subsequent test.

BDZ compounds induce their pharmacological actions by means of the allosteric modulation of GABA-A receptors thus activating the GABAergic inhibitory neurotransmission by increasing the frequency of chloride uptake (Study and Barker, 1981). There is a vast amount of data showing that memory impairment induced by $\mathrm{BDZ}$ is mediated by $\mathrm{BDZ}$ sites (Savic et al, 2005). It is probable that the neural mechanisms associated with both processes are critically modulated by inhibitory GABAergic neurotransmission even though reconsolidation and consolidation of extinction result in opposite behavioral outputs. Moreover; depending on the duration of the reactivation trial, the emergence of reconsolidation or the consolidation of extinction requires a reduced GABAergic neurotransmission. Previous reports (Pereira et al, 1989; Akirav et al, 2006; Akirav, 2007) have also shown that GABA-A agonist or diazepam administration, another BDZ compound, interrupted the fear extinction memory using different learning memory tasks, and McGaugh et al (1990) show that the administration of GABA-A receptors antagonist enhances extinction during testing. However, Harris and Westbrook $(1998,1999,2001)$ propose that GABA neurotransmission facilitates the acquisition and expression of extinction. In the works mentioned, BDZ-modulating agents were administered either prior to training or prior to the test (extinction training). Moreover, BDZ-sensitive GABA-A receptor binding in the amygdala is increased after extinction training (Chhatwal et al, 2005), and McCabe et al (2004) show that BDZ facilitates extinction by using a food-reinforced lever-press task in animals that had experienced several extinction sessions. In our case, MDZ was administered after a prolonged reactivation session and obviously, it did not influence the expression or the acquisition of extinction. Thus, procedural differences may account for the different effects on the extinction process observed between those reports and the present findings. Therefore, it seems reasonable to propose that GABAergic neurotransmission modulates different phases of extinction memory and the resultant effect will depend on: (1) the time of administration of the GABA-modulating drug, (2) the experience of the animal at the moment of administration, and (3) the experimental paradigm used. Finally, Myers and Davis (2002) advanced the view that activation of GABA-A sites would retard extinction if administered during the critical period of plasticity underlying extinction, whereas opposite effects would be obtained if they were injected prior to training or prior to the test.

An interesting finding of the present report is the timedependent stability gradient because as the time interval between training and reactivation increases, there is a clear reduction in the vulnerability to disruption after reactivation. A fear memory of 21 days was only vulnerable to MDZ at a $1.5 \mathrm{mg} / \mathrm{kg}$ dose with a reactivation session of 5 but not of $3 \mathrm{~min}$ and a remote memory of 36 days was only vulnerable to a higher $\mathrm{MDZ}$ dose $(3 \mathrm{mg} / \mathrm{kg})$. It is worthwhile to remark that when these old memories failed to show vulnerability to MDZ, the rats showed high levels of fear in the test session. In contrast, recent fear memories were prevented by MDZ both after a short reactivation trial and after MDZ $1 \mathrm{mg} / \mathrm{kg}$, a dose that was completely ineffective in older memories. Consistent with these results, emerging data have evidenced that as memories mature they become increasingly stable and immune to interfering agents after retrieval (Milekic and Alberini, 2002; Alberini, 2005; Suzuki et al, 2004; Frankland et al, 2006; Boccia et al, 2006; Eisenberg and Dudai, 2004). Interestingly, fear was absent 
early after training, but it was evident in remote memories, when animals were exposed to a novel context. As previously proposed (Wiltgen and Silva, 2007), this suggests that contextual fear memories generalize to other environments with the passage of time. In addition, MDZ administration after exposure to the nonassociated environment does not affect fear memory regardless of the interval between training and exposure to $\mathrm{B}$. Therefore, only reexposure to the associated context can induce memoryinduced lability to the disruptive effect of MDZ.

A longer reexposure is necessary to promote a destabilizing effect on a 21-day memory; whereas in older memories, a higher MDZ dose is necessary to induce a significant interference after retrieval. It has been proposed that the neural circuit underlying the storage of permanent memory differs from those implicated in the initial storage (Wiltgen et al, 2004) and that reorganization results in a greater stability (Dudai and Eisenberg, 2004; Alberini, 2005). Consequently, remote contextual fear memories are insensitive or less sensitive to disrupting drugs presumably because they are distributed through multiple cortical regions (Suzuki et al, 2004; Wiltgen et al, 2004; Frankland et al, 2004, 2006). Furthermore, longer duration of the reexposure session has greater destabilizing effect on memory traces than shorter reexposure. This latter view might explain the need to use a longer reexposure to promote a destabilizing effect on a 21-day memory and a higher MDZ dose to induce a significant interference of memory after retrieval in even older memories. With the same line of reasoning, a fear memory formed from a recent acquisition could be more accessible to destabilization with a shorter duration of the reactivation trial, and in turn, susceptible to interference with a lower MDZ dose probably because this consolidated memory is temporarily located in a more restricted neural network (Frankland et al, 2006; Frankland and Bontempi, 2005). Altogether, the results of this study demonstrate that MDZ interferes with the reconsolidation of a fear memory within a relatively restricted time window during reexposure (reactivation) in recent acquired memories. In longer reexposure, MDZ disrupts the consolidation of extinction. A longer duration of the reactivation session and higher doses of MDZ are required to interfere with the reconsolidation process of remote fear memories.

In summary, our findings demonstrate that the interplay between the variables studied in the present research, reexposure duration and memory age, is crucial in determining the degree of memory-induced lability after retrieval.

\section{ABBREVIATIONS}

$\mathrm{BDZ}$, benzodiazepine; A, conditioned context; B, novel context; CS, conditioned stimulus; US, unconditioned stimulus; GABA, $\gamma$-amino butyric acid; GABA-A, $\gamma$-amino butyric acid A receptor; i.p., intraperitoneally; $\mathrm{MDZ}$, midazolam; SAL, saline.

\section{ACKNOWLEDGEMENTS}

This work was supported by grants from SECyT, FONCyT, and CONICET to VAM and from FONCyT to HM. We thank Dolores Trebucq for English technical assistance.

\section{FINANCIAL DISCLOSURES}

SG Bustos is fellow of SECyT-UNC. Argentina. VA Molina is researcher of CONICET and full professor of the Universidad Nacional de Cordoba, Argentina. H Maldonado is researcher of CONICET and full professor of the Universidad de Buenos Aires, Argentina.

\section{REFERENCES}

Akirav I (2007). NMDA partial agonist reverses blocking of extinction of aversive memory by GABA(A) agonist in the amygdala. Neuropsychopharmacology 32: 542-550.

Akirav I, Raizel H, Maroun M (2006). Enhancement of conditioned fear extinction by infusion of the GABA agonist muscimol into the rat prefrontal cortex and amygdala. Eur J Neurosci 23: 758-764.

Alberini CM (2005). Mechanisms of memory stabilization: are consolidation and reconsolidation similar or distinct processes? Trends Neurosci 28: 51-56.

Anokhin KV, Tiunova AA, Rose SP (2002). Reminder effects: reconsolidation or retrieval deficit? Pharmacological dissection with protein synthesis inhibitors following reminder for a passive-avoidance task in young chicks. Eur J Neurosci 15: $1759-1765$.

Beracochea D (2006). Anterograde and retrograde effects of benzodiazepines on memory. Sci World J 6: 1460-1465.

Blanchard RJ, Blanchard DC (1969). Passive and active reactions to fear-eliciting stimuli. J Comp Physiol Psychol 68: 129-135.

Boccia MM, Blake MG, Acosta GB, Baratti CM (2006). Postretrieval effects of icv infusions of hemicholinium in mice are dependent on the age of the original memory. Learn Mem 13: 376-381.

Bouton ME (2004). Context and behavioral processes in extinction. Learn Mem 11: 485-494.

Bouton ME, Westbrook RF, Corcoran KA, Maren S (2006). Contextual and temporal modulation of extinction: behavioral and biological mechanisms. Biol Psychiatry 60: 352-360.

Bustos SG, Maldonado H, Molina VA (2006). Midazolam disrupts fear memory reconsolidation. Neuroscience 139: 831-842.

Chhatwal JP, Myers KM, Ressler KJ, Davis M (2005). Regulation of gephyrin and GABA-A receptor binding within the amygdala after fear acquisition and extinction. J Neurosci 25: 502-506.

Debiec J, Ledoux JE (2004). Disruption of reconsolidation but not consolidation of auditory fear conditioning by noradrenergic blockade in the amygdala. Neuroscience 129: 267-272.

Debiec J, LeDoux JE, Nader K (2002). Cellular and systems reconsolidation in the hippocampus. Neuron 36: 527-538.

Dickinson-Anson H, McGaugh JL (1993). Midazolam administered into the amygdala impairs retention of an inhibitory avoidance task. Behav Neural Biol 60: 84-87.

Dudai Y, Eisenberg M (2004). Rites of passage of the engram: reconsolidation and the lingering consolidation hypothesis. Neuron 44: 93-100.

Duvarci S, Nader K (2004). Characterization of fear memory reconsolidation. J Neurosci 24: 9269-9275.

Eisenberg M, Dudai Y (2004). Reconsolidation of fresh, remote, and extinguished fear memory in Medaka: old fears don't die. Eur J Neurosci 20: 3397-3403.

Eisenberg M, Kobilo T, Berman DE, Dudai Y (2003). Stability of retrieved memory: inverse correlation with trace dominance. Science 301: 1102-1104.

Forcato C, Burgos VL, Argibay PF, Molina VA, Pedreira ME, Maldonado H (2007). Reconsolidation of declarative memory in humans. Learn Mem 14: 295-303.

Frankland PW, Bontempi B (2005). The organization of recent and remote memories. Nat Rev Neurosci 6: 119-130. 
Frankland PW, Ding HK, Takahashi E, Suzuki A, Kida S, Silva AJ (2006). Stability of recent and remote contextual fear memory. Learn Mem 13: 451-457.

Frankland PW, Josselyn SA, Anagnostaras SG, Kogan JH, Takahashi E, Silva AJ (2004). Consolidation of CS and US representations in associative fear conditioning. Hippocampus 14: 557-569.

Gafford GM, Parsons RG, Helmstetter FJ (2005). Effects of posttraining hippocampal injections of midazolam on fear conditioning. Learn Mem 12: 573-578.

Harris JA, Westbrook RF (1998). Evidence that GABA transmission mediates context-specific extinction of learned fear. Psychopharmacology (Berl) 140: 105-115.

Harris JA, Westbrook RF (1999). The benzodiazepine midazolam does not impair Pavlovian fear conditioning but regulates when and where fear is expressed. $J$ Exp Psychol Anim Behav Process 25: 236-246.

Harris JA, Westbrook RF (2001). Contextual control over the expression of fear in rats conditioned under a benzodiazepine. Psychopharmacology (Berl) 156: 92-97.

Isoardi NA, Martijena ID, Carrer HF, Molina VA (2004). Increased fear learning coincides with neuronal dysinhibition and facilitated LTP in the basolateral amygdala following benzodiazepine withdrawal in rats. Neuropsychopharmacology 29: 1852-1864.

Izquierdo I, Medina JH (1991). GABAA receptor modulation of memory: the role of endogenous benzodiazepines. Trends Pharmacol Sci 12: 260-265.

Lee JL, Di Ciano P, Thomas KL, Everitt BJ (2005). Disrupting reconsolidation of drug memories reduces cocaine-seeking behavior. Neuron 47: 795-801.

Lee SH, Choi JH, Lee N, Lee HR, Kim JI, Yu NK et al (2008). Synaptic protein degradation underlies destabilization of retrieved fear memory. Science 319: 1253-1256.

McCabe C, Shaw D, Atack JR, Street LJ, Wafford KA, Dawson GR et al (2004). Subtype-selective GAGAergic drugs facilitate extinction of mouse operant behaviour. Neuropharmacol 46: 171-178.

McGaugh JL (2000). Memory-a century of consolidation. Science 287: 248-251.

McGaugh JL, Castellano C, Brioni J (1990). Picrotoxin enhances latent extinction of conditioned fear. Behav Neurosci 104: 264-267.

McNamara RK, dePape GE, Skelton RW (1993). Differential effects of benzodiazepine receptor agonists on hippocampal long-term potentiation and spatial learning in the Morris water maze. Brain Res 626: 63-70.

McNamara RK, Skelton RW (1991). Diazepam impairs acquisition but not performance in the Morris water maze. Pharmacol Biochem Behav 38: 651-658.

Milekic MH, Alberini CM (2002). Temporally graded requirement for protein synthesis following memory reactivation. Neuron 36: 521-525.
Myers KM, Davis M (2002). Behavioral and neural analysis of extinction. Neuron 36: 567-584.

Nader K (2003). Memory traces unbound. Trends Neurosci 26: 65-72.

Pedreira ME, Maldonado H (2003). Protein synthesis subserves reconsolidation or extinction depending on reminder duration. Neuron 38: 863-869.

Pedreira ME, Perez-Cuesta LM, Maldonado H (2004). Mismatch between what is expected and what actually occurs triggers memory reconsolidation or extinction. Learn Mem 11: 579-585.

Pereira ME, Rosat R, Huang CH, Godoy MG, Izquierdo I (1989). Inhibition by diazepam of the effect of additional training and of extinction on the retention of shuttle avoidance behavior in rats. Behav Neurosci 103: 202-205.

Przybyslawski J, Roullet P, Sara SJ (1999). Attenuation of emotional and non emotional memories after their reactivation: role of beta adrenergic receptors. J Neurosci 19: 6623-6628.

Przybyslawski J, Sara SJ (1997). Reconsolidation of memory after its reactivation. Behav Brain Res 84: 241-246.

Sangha S, Scheibenstock A, Lukowiak K (2003). Reconsolidation of a long-term memory in Lymnaea requires new protein and RNA synthesis and the soma of right pedal dorsal 1. J Neurosci 23: 8034-8040.

Savic MM, Obradovic DI, Ugresic ND, Bokonjic DR (2005). Memory effects of benzodiazepines: memory stages and types $v s$ binding-site subtypes. Neural Plast 12: 289-298.

Study RE, Barker JL (1981). Diazepam and (-)-pentobarbital: fluctuation analysis reveals different mechanisms for potentiation of gamma-aminobutyric acid responses in cultured central neurons. Proc Natl Acad Sci USA 78: 7180-7184.

Suzuki A, Josselyn SA, Frankland PW, Masushige S, Silva AJ, Kida S (2004). Memory reconsolidation and extinction have distinct temporal and biochemical signatures. J Neurosci 24: 4787-4795.

Thiebot MH (1985). Some evidence for amnesic-like effects of benzodiazepines in animals. Neurosci Biobehav Rev 9: 95-100.

Tronson NC, Taylor JR (2007). Molecular mechanisms of memory reconsolidation. Nat Rev Neurosci 8: 262-275.

Venault P, Chapouthier G, de Carvalho LP, Simiand J, Morre M, Dodd RH et al (1986). Benzodiazepine impairs and betacarboline enhances performance in learning and memory tasks. Nature 321: 864-866.

Walker MP, Brakefield T, Hobson JA, Stickgold R (2003). Dissociable stages of human memory consolidation and reconsolidation. Nature 425: 616-620.

Wiltgen BJ, Brown RA, Talton LE, Silva AJ (2004). New circuits for old memories: the role of the neocortex in consolidation. Neuron 44: 101-108.

Wiltgen BJ, Silva AJ (2007). Memory for context becomes less specific with time. Learn Mem 14: 313-317. 